\title{
SEISMOLOGICAL PRECURSORS TO A MAGNITUDE 5 EARTHQUAKE IN THE CENTRAL ALEUTIAN ISLANDS
}

\author{
E. R. ENGdAhL and C. Kisslinger \\ Cooperative Institute for Research in Environmental Sciences, \\ University of Colorado/NOAA, Boulder, Colorado, U.S.A.
}

(Received April 12, 1977)

\begin{abstract}
On February 22, 1976, a magnitude 5 thrust earthquake occurred at a depth of $25 \mathrm{~km}$ in the subduction zone near the Adak microearthquake network in the central Aleutians. The earthquake was located in a previously identified source volume with maximum dimensions of about $10 \mathrm{~km}$. This source volume falls within a larger seismotectonic feature characterized by a continuous band of seismicity along the arc in the depth range $17-27 \mathrm{~km}$. Within this band there was a period of decreased seismicity over a region $50 \mathrm{~km}$ wide, centered on the main shock, beginning about $41 / 2$ months prior to the earthquake. During a 5 week period before the earthquake, six small foreshocks occurred in the smaller source volume. High-resolution hypocenter locations showed a clear alignment of the foreshocks, progressing toward the location of the main event. The line of progression was roughly parallel to the direction of slip in the mainshock. The first and last foreshocks were characterized by thrust focal mechanisms common to earthquakes occurring during 'normal' periods. The remaining foreshocks were also thrust mechanisms, but with the principal axes of stress rotated nearly $90^{\circ}$ on the basis of observed first motions and $S / P$ amplitude ratios. For these same foreshocks there was also a suggestion of a very small $P$ delay to a station with a ray going through the hypocentral region of the mainshock.
\end{abstract}

The Adak seismograph network was established in late July, 1974 and has been in nearly continual operation since that time, providing a long continuous base of seismicity data. The network now has dimensions of about 50 by $150 \mathrm{~km}$ along the Aleutian arc, centered on Adak, and consists of 11 high-gain, high-frequency, two-component seismic systems on six islands (see Fig. 1). All the data are radiotelemetered to the U.S. National Weather Service Adak Observatory where they are recorded on $16 \mathrm{~mm}$ Develocorder film along with short-period three-component data from the Adak (ADK) Benioffs.

$P$ and $S$ arrival times are read to a precision of $\pm 0.03 \mathrm{sec}$ from the film for all earthquakes occurring near the network. Duration of the wave coda is also measured for magnitude estimation. The earthquakes are located using the $P$ and $S$ arrival times and a model of the crust beneath Adak determined from seismic refraction profiles (SHOR, 1964). A velocity ratio $\sqrt{3}(\sigma=1 / 4)$ is assumed and station corrections by source region applied to shallow events. 





The primary purposes of this network are to develop concurrently principles and techniques for earthquake prediction and an improved understanding of earthquake mechanisms and tectonics in an island arc setting. The fine details of plate subduction are not well understood, but may well provide the key to earthquake prediction in an island arc. Accurate hypocenter and focal mechanism determinations have enabled us to examine the subduction process in great detail in the central Aleutians. We report here observations of seismological phenomena precursory to a magnitude 5 earthquake in the central Aleutian islands and their relation to the regional tectonics.

Epicenters for all earthquakes located with data from the network during a $21 / 2$ year period (July, 1974 through December, 1976) are shown in Fig. 1. The general
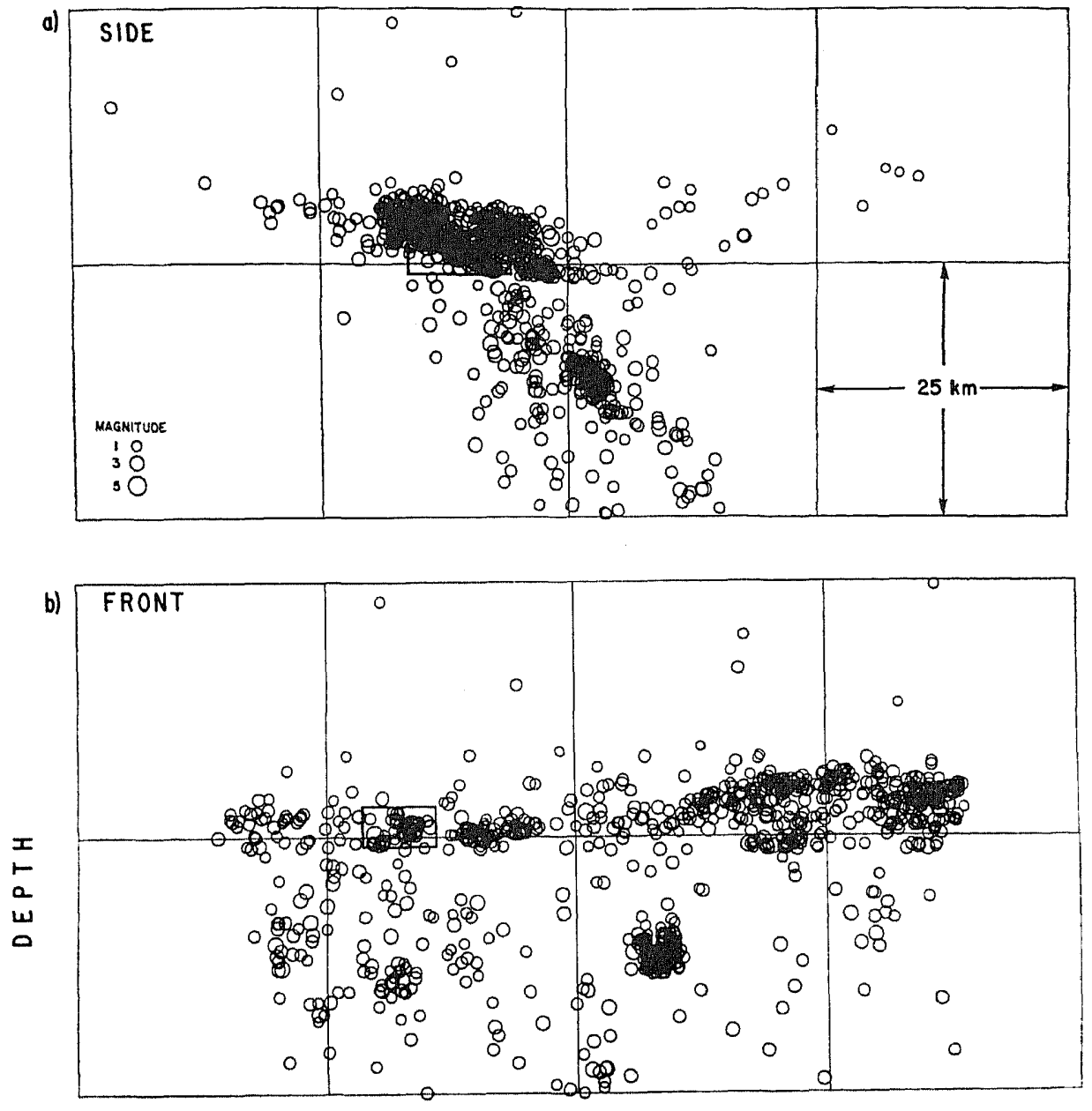

DISTANCE

Fig. 2. Side and frontal sections of shallow seismicity within larger rectangle of Fig. 1. Horizontal axis in side view is distance to center of curvature of the arc and in front view arc distance at an arbitrary reference radius to this center of curvature. 
characteristics of this seismicity have been described by ENGDAHL (1977). For purposes of this paper we note again three prominent features in this figure:

(1) the shallow $(0-50 \mathrm{~km})$ seismicity occurs primarily beneath the south slope of the Aleutian arc ridge, south of the network; (2) there seems to exist a structural boundary beneath the east and west halves of the network, marked by changing characteristics in the seismicity and in the bathymetry of the region; (3) except for the Aleutian Trench, there is little or no seismicity south of that plotted, on the Aleutian Terrace. We confine our attention in this paper to a region in the eastern section outlined by the large rectangle in Fig. 1, characterized by clearly defined localized concentrations in seismic activity. Within one of these small concentrated volumes, outlined by the small rectangle in Fig. 1 (hereafter, called the SW1 region), a magnitude 5 thrust earthquake occurred on February 22, 1976 at a depth of $25 \mathrm{~km}$. We will examine the space-time distribution of shallow seismicity within the large rectangle and the fine details of seismicity within the SW1 region.

Figure 2 shows plots of the shallow seismicity within the large rectangle of Fig. 1 in both side and front views. Striking features are the occurrence of a nearly continuous band of active seismicity along the arc in the depth range $17-27 \mathrm{~km}$ and the lack of any significant seismicity above $17 \mathrm{~km}$. Small volumes within this band are currently very active and have produced earthquakes large enough to be recorded teleseismically. The SW1 region, identified by the small rectangle in Fig. 1, appears in the sections shown (the rectangles) as a small cluster of activity within the active band.

Let us hypothesize that the active band of seismicity shown in Fig. 2 is a major controlling influence in the occurrence of larger earthquakes along the arc. Hence,

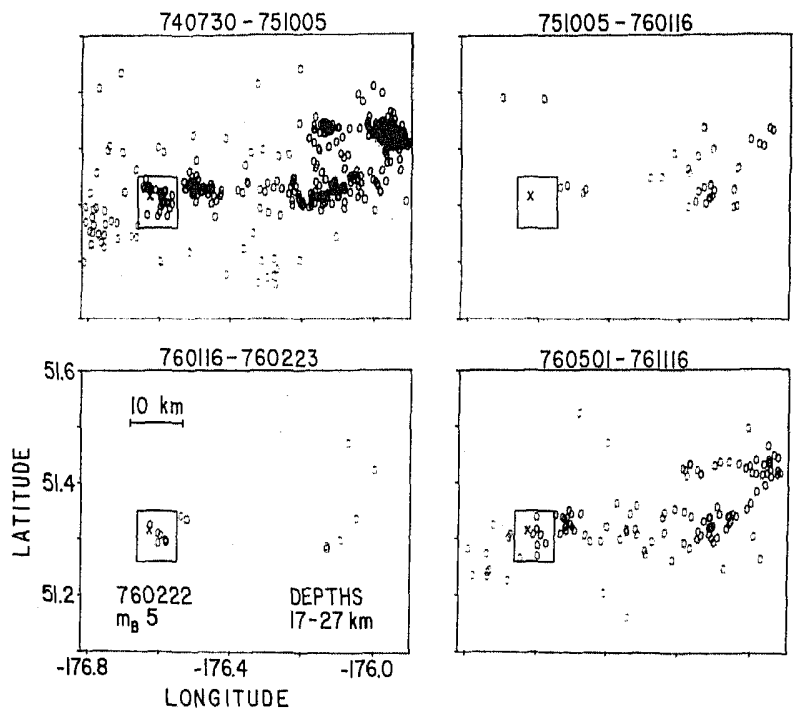

Fig. 3. Time history of seismicity in the depth range $17-27 \mathrm{~km}$ within the large rectangle of Fig. 1. The SW1 source volume of the $m_{B} 5$ earthquake (the $x$ in these plots) is indicated by the small rectangle. 
the time dependency of seismicity in this band may furnish evidence for phenomena precursory to impending large earthquakes. Figure 3 displays the seismicity within the large rectangle of Fig. 1, but only for depths between 17 and $27 \mathrm{~km}$, for four time periods. The small rectangle in this figure, the SW1 region, corresponds to the same small volume outlined in Figs. 1 and 2 . The $\times$ marks the location of the magnitude 5 earthquake which occurred during the period of time covered by the plot in the lower left-hand corner. The period 740730-751005 is representative of the 'normal' background seismicity. Small continually active source volumes, including SW1, are easily identifiable. The periods 751005-760116 and 760116-760223, however, mark a dramatic change in this pattern. The former period shows a dramatic decrease in the rate of seismic activity over a large region around the source of the $m_{B} 5$ earthquake (the $\times$ ) and no activity at all within the SW1 region. This decrease in seismicity continues into the latter period, about five weeks before the mainshock, except for six small events $\left(m_{B} 2.0-3.0\right)$, now recognized as foreshocks, which occurred in the smaller SW1 source volume, close to the mainshock. The network went down after a lightning strike on February 23, 1976, so that we had no data between February 23 and May 1, 1976, but after 760501 the last plot shows that the seismicity seems to have returned to its original earlier background level.

These observations previously described prompted us to do a more intensive study of the seismicity within the small SW1 source volume in which the mainshock occurred. The small size of this volume required high-resolution hypocenter locations, which we achieved by using $\mathrm{P}$ and $\mathrm{S}$ station corrections unique to that volume, enabling us to reduce rms residuals to $0.10 \mathrm{sec}$ or less. We also used observed first motions and ADK $S / P$ amplitude ratios to classify characteristic focal mechanisms within the volume into the three types shown in Fig. $4(\mathrm{~N}, \mathrm{~A}, \mathrm{~B})$, as well as to determine the mainshock source mechanism $(X)$. All are thrust mechanisms but of different orientation.

Hypocenters in the SW1 region are plotted in plan view and in section in Figs. $4(a)$ and $4($ b) by a symbol which identifies their focal mechanism class. There appear to be some obvious spatial separations of the focal mechanisms. A deeper group to the northwest and close to the mainshock depth appears to be all of the $\mathrm{N}$ type. Of special interest is the fact that there was no further activity in the deeper group after the mainshock during the remainder of 1976. The A type appears to be centered in a small cluster to the northeast at a depth slightly greater than $24 \mathrm{~km}$. The A group all occurred between August, 1974 and September, 1975, and the distribution suggests that they are associated with a minor separate structure, not related to the main event. The $\mathrm{B}$ type, however, seems to be interspersed with shallow $\mathrm{N}$ mechanisms. This spatial regionalization of focal mechanisms and apparent shallow dipping fault plane, over which the seismicity in this small SW1 volume is distributed, gives us added confidence that these hypocenters are highly accurate $(<1 \mathrm{~km})$, at least in the relative sense.

The role of the B mechanisms becomes clearer in Fig. 4(c), in which only the foreshock period, 760116-760223, is plotted. The connecting arrows reflect the time 


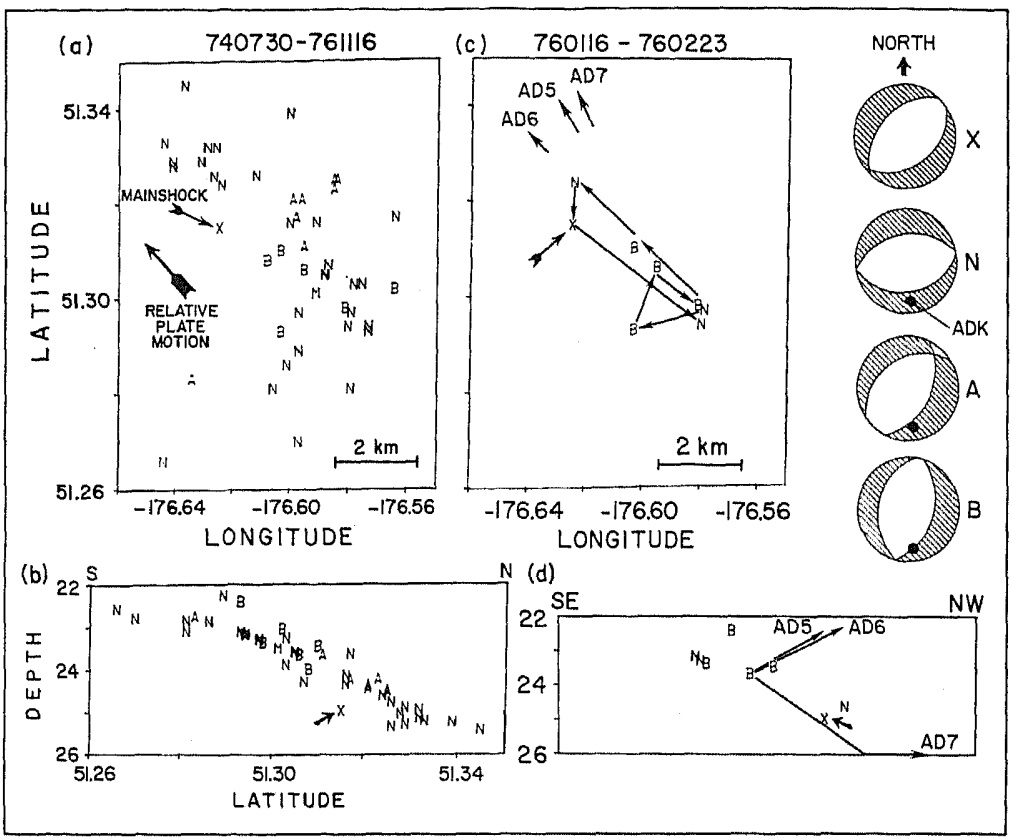

Fig. 4. (a) Map view of seismicity within small source volume (SW1 region) plotted by symbols corresponding to focal mechanism classes shown on right. (b) N-S depth section of 4(a). (c) Map view of foreshocks and aftershock period. Connecting arrows show time progression of events. Other arrows show ray directions to stations AD5, $\mathrm{AD6}$, and $\mathrm{AD7}$ (the location of these stations is identified in Fig. 1). (d) Ray directions to stations plotted in NW-SE section. AD5 and AD6 are upgoing rays and AD7 is critically refracted on a model boundary at $26 \mathrm{~km}$. Focal mechanism classes on the right side of this figure are lower hemisphere projections with the regions of dilatations shaded. $S / P$ amplitude ratios were read at station ADK.

progression in occurrence of these events and seem to show a spatial progression along a line roughly parallel to the direction of slip in the mainshock. The first and last foreshocks, which were also the largest, were characterized by thrust mechanisms of the $\mathrm{N}$ type, common to earthquakes occurring during 'normal' periods. The remaining four foreshocks were also thrust mechanisms, but with the principal axes of stress rotated nearly $90^{\circ}$. A similar effect has also been recently reported by MANTIS and LINDH (1976) for foreshocks immediately before the Oroville earthquake, possibly reflecting a progressive failure in the volume surrounding the mainshock. There was only one aftershock in the $24 \mathrm{hr}$ period following the central Aleutian mainshock. It had an $\mathrm{N}$-type mechanism and was located close to the first foreshock.

The location of the foreshocks at shallower depths than the mainshock also affords us a unique opportunity to search for $P$ delays that might be related to preparation of the immediate mainshock source region. $P$ delays are preferred to Wadati diagrams because of special problems introduced by the station-source geometry, data drop-out, and complex geology of the region (PRICE et al., 1976). The ray paths 


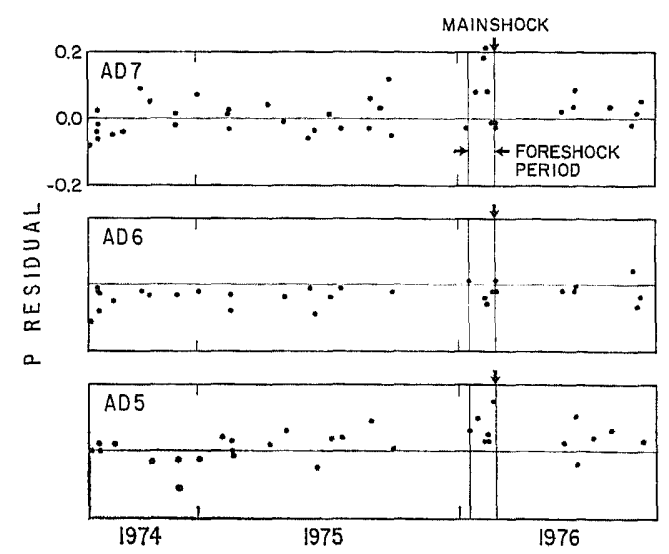

Fig. 5. $P$ residuals (in second) of SW1 earthquakes at stations AD5, AD6, and AD7 plotted as a function of time.

to stations AD5, AD6, and AD7 are shown in Fig. 4(c) and 4(d) (see also Fig. 1). $\mathrm{AD} 5$ and $\mathrm{AD} 6$ are upgoing rays and $\mathrm{AD} 7$ receives a first arrival which has been critically refracted along a model boundary at $26 \mathrm{~km}$. The $A D 7$ ray passes through or close to the source region of the mainshock. To search for $P$ delays we recomputed all the hypocenters in the SW1 region but without using the $P$ arrival at these stations (the $\mathrm{S}$ was used). The resulting $P$ residuals are plotted as a function of time in Fig. 5. Even though only slightly above the noise, $P$ waves from foreshocks of the $\mathrm{B}$ type to $\mathrm{AD} 7$ seem to have been systematically delayed, while $\mathrm{P}$ waves to AD5 and AD6 are not clearly affected. Two of the foreshocks have delays to AD7 which are 2-3 times the standard deviation of a single residual. All were carefully rechecked for validity and had clear onsets which could be read to $0.03 \mathrm{sec}$. With the exception of the B type, there seemed to be no other clear relation of residuals to mechanism class. A possible explanation of the observed delay other than reduced $P$ velocity along the path has been suggested by Minster (1977) and SutEaU and Minster (1977). They propose that the group delay at the source is a function of frequency. This could produce a variation of tenths of a second to several seconds in the difference between $P$ and $S$ group delays over the frequency band, either due to attenuation or the source. In particular, it is shown that the 'visual' arrival time is sensitive to the high frequency end of the absorption band. Our data suggest that the delays, if real, are a path effect and not a source effect.

These observations are certainly provocative as they seem to suggest a change in material properties in the source region of the mainshock. This change is demonstrated by a period of decreased seismicity over a larger region, a shorter period of clearly identifiable foreshocks, a reorientation of the principal stress axes during the foreshock period and the possibility of a $P$ delay. A precursory decrease in seismicity in a region around the future hypocenter has been suggested by several investigators. Although dilatancy hardening could explain this behavior, we cannot determine the adequacy of this explanation from the present data. 
Other interesting features require explanation. Do small active source volumes like SW1 define the maximum source dimensions for larger earthquakes within the 17-27 km band? Does the occurrence of a larger earthquake that clearly cuts across two or more of these source volumes signal the imminence of an arc-breaking potentially destructive earthquake? Do arc-breaking earthquakes initiate in this band? What is the significance of the apparent lid on the shallow seismicity at $17 \mathrm{~km}$ ? The role of foreshocks and these questions are highly relevant to earthquake prediction research in an active subduction zone. As we continue to accumulate and further refine existing data, we will be seeking the answers to these questions.

The continual success of the field operation in the Adak Island region is due in large part to helicopter support provided by the U.S. Naval Station Adak. This work was supported under U.S.G.S. Contract No. 14-08-0001-14581.

\section{REFERENCES}

ENGDahl, E. R., Seismicity and plate subduction in the central Aleutians, in Island Arcs, Deep Sea Trenches and Back-Arc Basins, Maurice Ewing Series 1, edited by M. Talwani and W. C. Pitman III, pp. 259-272, Amer. Geophys. Union, 1977.

Mantis, C. and A. LindH, The Oroville foreshocks with an apparent coseismic change in fault plane orientation with short term precursor, EOS, Trans. Am. Geophys. Union (abstr.), 57, 956, 1976.

Minster, J. B., Transient and impulse response of a standard linear solid, EOS, Trans. Am. Geophys. Union (abstr.), 58, 439, 1977.

Price, S. J., E. R. ENGDAhL, and C. KissLinger, Effects of earth structure on the Wadati diagram, EOS, Trans. Am. Geophys. Union (abstr.), 57, 957, 1976.

SHor, G. G., Structure of the Bering Sea and the Aleutian Ridge, Marine Geol., 1, 213-219, 1964.

SuteAu, A. M. and J. B. Minster, Source mechanism, attenuation, and the question of body wave dispersion, EOS, Trans. Am. Geophys. Union (abstr.), 58, 439, 1977. 